Jens Bisky

Poesie der Baukunst

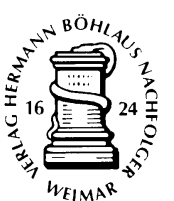




\author{
Jens Bisky
}

\title{
Poesie der Baukunst
}

\author{
Architekturästhetik \\ von Winckelmann bis Boisserée
}


Die Deutsche Bibliothek - CIP-Einheitsaufnahme

Bisky, Jens:

Poesie der Baukunst : Architekturästhetik von Winckelmann bis Boisserée / Jens Bisky. - Weimar :

Verlag Hermann Böhlaus Nachfolger Weimar, 2000

ISBN 978-3-7400-1119-2

ISBN 978-3-7400-1119-2

ISBN 978-3-476-01498-6 (eBook)

DOI 10.1007/978-3-476-01498-6

Dieses Werk einschließlich aller seiner Teile ist urheberrechtlich geschützt. Jede Verwertung außerhalb der engen Grenzen des Urheberrechtsgesetzes ist ohne Zustimmung des Verlages unzulässig und strafbar. Das gilt insbesondere für Vervielfältigungen, Übersetzungen, Mikroverfilmungen und die Einspeicherung und Verarbeitung in elektronischen Systemen.

(C) 2000 Springer-Verlag GmbH Deutschland

Ursprünglich erschienen bei Verlag Hermann Bohlaus Nachfolger Weimar 2000 


\section{Inhalt}

Prolog: Poesie der Baukunst

Das Vergnügen der Betrachtung

Der Kritiker Vitruvs

Johann Joachim Winckelmanns Anmerkungen über die Baukunst der alten Tempel $\ldots \ldots \ldots$

Der gelehrte Architekt

Christian Traugott Weinligs Briefe über Rom _. . . . . . . . . . . . . . . . . 20

Der philosophische Kritiker

Johann Georg Sulzers Artikel »Baukunst $\ldots \ldots \ldots$. . . . . . . . . . . . . . . . . 30

Das fühlende Genie

Johann Wolfgang Goethes Aufsatz $»$ Von deutscher Baukunst« . . . . . . . . . . . . . . 37

Italienische Erfahrungen $\ldots \ldots \ldots \ldots \ldots \ldots \ldots \ldots$

»Lebendigste Form«

Wilhelm Heinses Wahrnehmung der Architektur in Italien . . . . . . . . . . . . . 47

$»$... wie in einem Wohnzimmer«

Karl Philipp Moritz' Beschreibung der Peterskirche . . . . . . . . . . . . . . . . . . . 62

Die Fiktion der Baukunst

Goethes architekturtheoretische Aufsätze von 1788 und $1795 \ldots \ldots$. . . . . . . . . 70

Die Praxis der Einbildungskraft $\ldots \ldots \ldots \ldots \ldots \ldots \ldots \ldots$

Anzaubern

Architektur und Einbildungskraft in Hirschfelds Theorie der Gartenkunst . . . . . . . . . . . . . 81

Rührende Architektur

Lektüre der Formen in den Untersuchungen über den Charakter der Gebäude . . . . . . . . . . . . 100

»Griechisch« und »Gothisch«

Programme einer Architekturgeschichte . . . . . . . . . . . . . . . . . . . 118

Der beobachtende Architekt

Friedrich Gillys Architekturbeschreibungen . . . . . . . . . . . . . . . . . . . . 138 


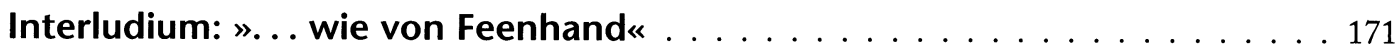

Wunderbare Bauten . . . . . . . . . . . . . . . . . . . . . . . . 179

Die Schauer des Erhabenen

Georg Forsters Besuch im Kölner Dom . . . . . . . . . . . . . . . . . . . . . . . . . . 181

Klosterbruders Peterskirche

Die Poetisierung architektonischer Formen bei Wilhelm Heinrich Wackenroder

und Ludwig Tieck . . . . . . . . . . . . . . . . . . . . . . . . . . . . . . . . . . . . . 191

Romantische Architekturästhetik . . . . . . . . . . . . . . . . . . . . . . . . 201

Symbolisierende Baukunst

August Wilhelm Schlegels Vorlesungen über Architektur . . . . . . . . . . . . . . . . . . . 203

Der Stil der Phantasie

Friedrich Schlegels Briefe auf einer Reise . . . . . . . . . . . . . . . . . . . . . . . . 217

Exkurs: Bernhard Hundeshagens Architekturpublikationen . . . . . . . . . . . . . . . . . 229

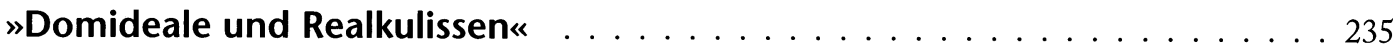

»Frappant! «

Malerischer Historismus und »reiner Bau« - Karl Friedrich Schinkels erste Italienreise . . . . . . 238

Ideenarchitektur

Karl Friedrich Schinkels romantische Entwürfe . . . . . . . . . . . . . . . . . . . . . . . 248

». . in einem unendlichen Bau an der Stadt Gottes auf Erden« . . . . . . . . . 261

Neigung und Methode

Boisserées Entschluss, Kunsthistoriker zu werden . . . . . . . . . . . . . . . . . . . . 265

Geschichte und Beschreibung

Boisserées Domwerk in der ersten Auflage . . . . . . . . . . . . . . . . . . . . . . . . . 274

Teil und Ganzes . . . . . . . . . . . . . . . . . . . . . . . . . . . . . . . . 278

Liturgie und Symbolik . . . . . . . . . . . . . . . . . . . . . . . . . . . . . 281

Dom und Stadt . . . . . . . . . . . . . . . . . . . . . . . . . . . . . . 285 
Der alte Herr und sein romantischer Freund

Goethes zweite Beschreibung des Straßburger Münsters . . . . . . . . . . . . . . . . . . . . 291

Exkurs: Über die musikalische Analogie . . . . . . . . . . . . . . . . . . . . . . . . . . 299

Vom Einfluss der Religion

Boisserées Studien zur Architekturgeschichte . . . . . . . . . . . . . . . . . . . . . . 303

Epilog: Distanz zur Gegenwart . . . . . . . . . . . . . . . . . . 321

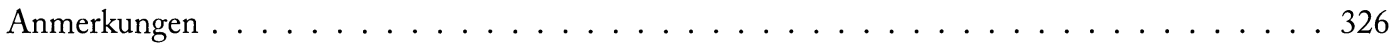

Literaturverzeichnis . . . . . . . . . . . . . . . . . . . . . . 368

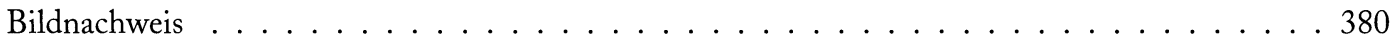

Personenregister . . . . . . . . . . . . . . . . . . . . 381

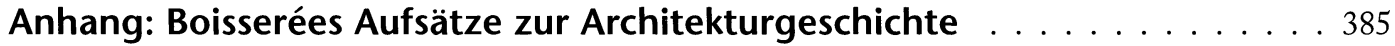

Von dem Einflusse der Religion auf die Kunst der alten Welt . . . . . . . . . . . . . . . . . . 389

Übersicht der Geschichte der Kirchenbaukunst . . . . . . . . . . . . . . . . . . . . . . . . . . . . . . . . . . . . . . . . . . . . . . .

Flüchtige Übersicht der Geschichte der Baukunst . . . . . . . . . . . . . . . . . . . . . . . . . 435

Über den Mittelthurm zum Kölner Dom . . . . . . . . . . . . . . . . . . . . . . . . . . . . 442 